\title{
Reaction Mechanism of the Trinuclear Zinc Enzyme Phospholipase C: A Density Functional Theory Study
}

\author{
Rong-Zhen Liao, ${ }^{\dagger,}$ Jian-Guo Yu, and Fahmi Himo ${ }^{*}, \dagger$ \\ Department of Organic Chemistry, Arrhenius Laboratory, Stockholm University, SE-10691 Stockholm, Sweden, \\ and College of Chemistry, Beijing Normal University, Beijing, 100875, People's Republic of China.
}

Received: November 19, 2009; Revised Manuscript Received: January 14, 2010

\begin{abstract}
Phosphatidylcholine-preferring phospholipase $\mathrm{C}$ is a trinuclear zinc-dependent phosphodiesterase, catalyzing the hydrolysis of choline phospholipids. In the present study, density functional theory is used to investigate the reaction mechanism of this enzyme. Two possible mechanistic scenarios were considered with a model of the active site designed on the basis of the high resolution X-ray crystal structure of the native enzyme. The calculations show that a Zn1 and Zn3 bridging hydroxide rather than a Zn1 coordinated water molecule performs the nucleophilic attack on the phosphorus center. Simultaneously, Zn2 activates a water molecule to protonate the leaving group. In the following step, the newly generated $\mathrm{Zn} 2$ bound hydroxide makes the reverse attack, resulting in the regeneration of the bridging hydroxide. The first step is calculated to be ratelimiting with a barrier of $17.3 \mathrm{kcal} / \mathrm{mol}$, in good agreement with experimental kinetic studies. The zinc ions are suggested to orient the substrate for nucleophilic attack and provide electrostatic stabilization to the dianionic penta-coordinated trigonal bipyramidal transition states, thereby lowering the barrier.
\end{abstract}

\section{Introduction}

The enzymes of the phospholipase C (PLC) family act as phosphodiesterases to catalyze the hydrolysis of phospholipids, yielding a diacylglycerol (DAG) and a phosphorylated headgroup (Scheme 1). ${ }^{1,2}$ In mammalian systems, DAG acts as a secondary messenger in signal transduction, responsible for the activation of membrane-bound protein kinase C. ${ }^{1,3}$ Mammalian PLCs have not been purified and the genes encoding these enzymes have not been cloned. ${ }^{2 b}$ In Bacillus cereus, the phosphatidylcholine-preferring PLC $\left(\mathrm{PLC}_{\mathrm{BC}}\right)$ is an extracellular monomeric enzyme containing 245 amino acids. It also catalyzes the hydrolysis of phosphatidylethanolamine and phosphatidylserine but with lower efficiency. ${ }^{2 a}$ The antigenic similarity of $P C_{B C}$ with the mammalian counterpart suggests that PLC $C_{B C}$ may be a useful model for the poorly characterized mammalian enzymes. $^{4}$

The X-ray crystal structure of PLC $_{\mathrm{BC}}$ has been determined to high resolution $(1.5 \AA)$ and revealed that the active site (shown in Figure 1) contains a trinuclear zinc cluster, wherein $\mathrm{Zn} 1$ and $\mathrm{Zn} 3$ are bridged by an aspartate (Asp122) and an oxygen species (labeled as $\mathrm{O}_{\mathrm{A}}$ ), and $\mathrm{Zn} 2$ is bridged to $\mathrm{Zn} 3$ via an oxygen species. ${ }^{5}$ In addition, five histidines (His14, His69, His118, His128, and His142), an aspartate (Asp55), a glutamate (Glu146), and a tryptophan (Trp1) are coordinated to the three zinc ions, as shown in Figure 1.

There are two other known trinuclear zinc phosphodiesterases. One is nuclease P1 (NP1), ${ }^{6}$ which catalyzes the hydrolysis of the $\mathrm{P}-\mathrm{O}^{\prime}$ ' bond of single-strand DNA and has an almost identical disposition and coordination of the three zinc ions in the active site. The other is endonuclease IV, ${ }^{7}$ which catalyzes the cleavage of $\mathrm{P}-\mathrm{O}^{\prime}$ bond at the $5^{\prime}$ of abasic sites, producing a $3^{\prime}$-hydroxyl group and a $5^{\prime}$-terminal phosphate. It exhibits an

* Corresponding author. E-mail: himo@organ.su.se. Tel: +46 8161094. Fax: +468154908 .

Stockholm University.

* Beijing Normal University.
SCHEME 1: Reaction Catalyzed by PLC

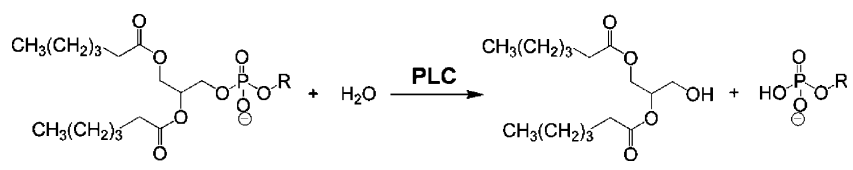

$(\alpha / \beta)_{8}$ TIM barrel fold which differs from the all $\alpha$-helical folds in PLC $\mathrm{BC}_{\mathrm{BC}}$ and NP1.

Phosphate hydrolysis and transfer is of enormous importance in biology, as it is involved in, for example, signaling, regulation, and energy transduction. ${ }^{8}$ Computational studies have over the years provided great insights into these important processes. ${ }^{9}$ The reaction mechanism of phosphodiesterases is in general

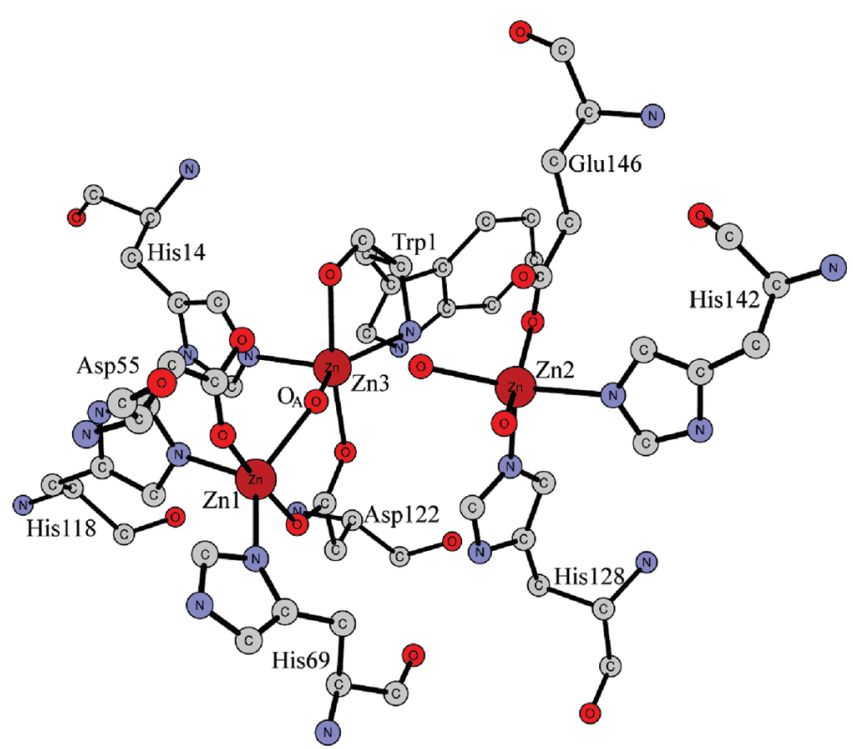

Figure 1. X-ray structure of the trizinc active site in $P_{L C} C_{B C}$ (coordinates taken from PDB entry $1 \mathrm{AH} 7^{5}$ ). 


\section{SCHEME 2: Proposed Mechanistic Scenarios for the Reaction of PLC $_{\mathrm{BC}}$}

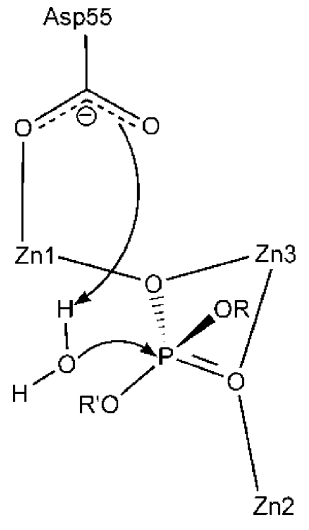

Mechanism A

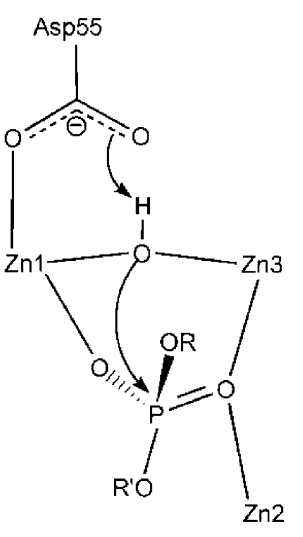

Mechanism B believed to proceed through an in-line attack by an activated water molecule or a hydroxide on the substrate phosphorus center, followed by collapse of the resulting pentacoordinated species with an inversion of the stereochemistry at the phosphorus center. ${ }^{10}$ The catalytic mechanism of $\mathrm{PLC}_{\mathrm{BC}}$ has been the subject of discussion for a long time. Earlier studies focused on the substrate binding mode. The X-ray structure of $\mathrm{PLC}_{\mathrm{BC}}$ in complex with inhibitor 3,4-di-n-hexanoyloxybutyl-1-phosphocholine suggested that the bridging hydroxide is displaced by one of the phosphate oxygens of the substrate during the formation of the enzyme substrate complex. ${ }^{11}$ In addition, there have been a lot of efforts to identify the role of the Asp55, Glu146, and Glu4 residues in the active site. Mutagenesis studies suggested that Glu146 serves as a critical ligand of $\mathrm{Zn} 2$, stabilizing the secondary and tertiary structures of the enzyme, ${ }^{12}$ while the second-shell Glu4 is primarily involved in substrate binding through electrostatic interaction with the positive charge of the choline moiety. ${ }^{13}$ Asp55 was proposed to play a critical role in catalysis, since its mutation resulted in an up to $10^{6}$-fold decrease of catalytic activity. ${ }^{13 \mathrm{c}}$ However, another study showed that Asp55 is not critical for the structural integrity of the enzyme. ${ }^{11 \mathrm{c}}$ Molecular dynamics simulations suggested that Asp55 is a likely candidate for the general base needed to deprotonate the nucleophilic water molecule. ${ }^{14}$ These results suggest the general mechanism called mechanism A in Scheme 2. However, the enzyme-inhibitor complex represents a static and nonproductive picture of this enzyme. One cannot rule out the possibility that the hydroxide is still at the bridging position after the formation of the Michaelis complex. Molecular modeling studies suggested that the hydrolysis takes place through an in-line attack by the bridging hydroxide (mechanism $\mathrm{B}$ in Scheme 2). ${ }^{15}$ This mechanistic proposal has also been put forward for several dinuclear zinc enzymes, ${ }^{16}$ as well as the two aforementioned trinuclear zinc enzymes NP1 ${ }^{6}$ and endonuclease IV. ${ }^{7}$

The two suggested mechanisms are thus quite different in nature. Here, theoretical calculations can be of great value in discriminating between different substrate binding modes and reaction mechanisms. In this study, we use the quantum chemical cluster approach to investigate the reaction mechanism of PLC $\mathrm{BC}_{\mathrm{BC}}$. We designed a model of the active site on the basis of the crystal structure (PDB entry: $1 \mathrm{AH} 7),{ }^{5}$ and employed the hybrid functional $\mathrm{B} 3 \mathrm{LYP}^{17}$ to calculate the potential energy profiles for the two mechanistic scenarios depicted in Scheme 2. This methodology has been successfully applied to study a wide variety of enzymes. ${ }^{18}$ In particular, in the last couple of years, the reaction mechanisms of several dinuclear zinc enzymes were studied and a large amount of mechanistic insight was uncovered. ${ }^{19}$ The quantum chemical approach has been shown to be accurate enough to distinguish between reaction mechanisms. The error in B3LYP has been estimated to be 3-5 $\mathrm{kcal} / \mathrm{mol}$ for this kind of systems. ${ }^{18 \mathrm{~g}}$ For comparing relative barriers, the accuracy is expected to be higher.

\section{Computational Details}

The present theoretical calculations were carried out using density functional theory (DFT) with the B3LYP functional, ${ }^{17}$ as implemented in the Gaussian03 program package. ${ }^{20}$ Geometry optimizations were performed with the $6-311+\mathrm{G}(2 \mathrm{~d})$ basis set for the phosphorus and the five oxygen atoms around it (i.e., including the oxygens of the nucleophile and the leaving group), the effective core potential LANL2DZ ${ }^{21}$ for $\mathrm{Zn}$, and the 6-31G(d,p) basis set for all other atoms. The use of the $6-311+G(2 d)$ basis set is to ensure a proper description of the pentacoordinated phosphorus complex. On the basis of these optimized geometries, more accurate energies were obtained by performing single-point calculations with the larger basis set $6-311+G(2 d, 2 p)$ for all atoms.

To estimate the effect of the protein surrounding that is not explicitly included in the quantum chemical model, single-point calculations on the optimized structures were carried out with the conductor-like polarizable continuum model $(\mathrm{CPCM})^{22}$ method at the same level of theory as geometry optimizations. The dielectric constant was chosen to be 4, which is the standard value used in modeling protein surroundings. Recent studies from our laboratory have shown that the effect of the dielectric surrounding diminishes with a growing model size. ${ }^{23}$ At a model size of ca. 150-200 atoms, the effect almost vanishes and the choice of the dielectric constant thus become irrelevant. Frequency calculations were performed to obtain zero-point energies (ZPE) and to confirm the nature of the various stationary points. In the geometry optimizations, certain atoms were kept fixed to their crystallographically observed positions (see below). This procedure gives rise to several small imaginary frequencies, typically on the order of $10 \mathrm{i}-30 \mathrm{i} \mathrm{cm}-1$. These do not contribute significantly to the ZPE and can thus be ignored. However, they make the calculations of the harmonic entropy effects inaccurate. Therefore, entropy was not considered in the current study. In any case, entropy effects are expected to be rather small and do not alter any mechanistic conclusion, as shown, for example, by QM/MM free energy calculations on histone lysine methyltransferase. ${ }^{24}$

\section{Active Site Model}

The active site model used in the present calculations is constructed on the basis of the crystal structure of native PLC $_{\mathrm{BC}}$ (PDB entry 1AH7, Figure 1). ${ }^{5}$ The model consists of the three zinc ions along with their first-shell ligands. Zn1 and Zn3 are bridged by Asp122 and a hydroxide. $\mathrm{Zn} 1$ is coordinated by Asp55, His69, and His118, Zn2 is coordinated by His128, His142, and Glu146, and Zn3 is coordinated by Trp1 and His 14. The amino acid residues were truncated so that in principle only the functional coordination groups, extended by one or two carbons, were kept in the model. Thus the histidines were represented by methylimidazoles, aspartates, and glutamates by acetates, and the terminal part of Trp1 by aminoacetaldehyde. A simple model substrate, dimethyl phosphate, was used, which is adequate for the purposes of this mechanistic study. Hydrogen atoms were added manually. During the geometry optimizations, 

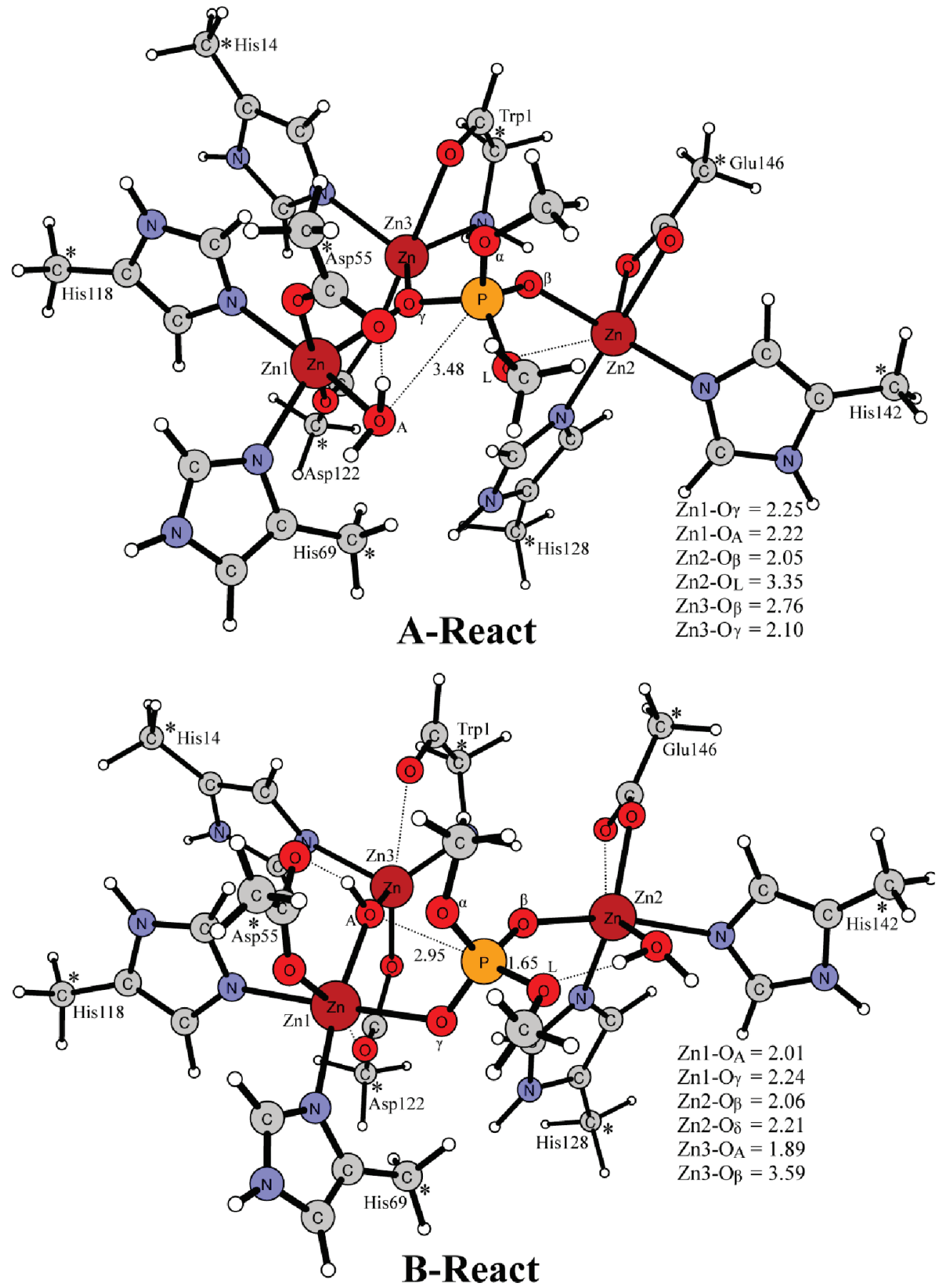

Figure 2. Optimized structures for the active site model of $\mathrm{PLC}_{\mathrm{BC}}$ in two substrate binding modes. Atoms marked with asterisks were fixed at their $\mathrm{X}$-ray structure positions during the geometry optimizations. Distances are given in angstrom $(\AA)$.

truncation atoms were kept fixed at their crystallographically observed positions to keep the optimized structures close to the experimental one. These centers are indicated by asterisks in the figures below.

To study the two mechanisms discussed in the Introduction (Scheme 2), two models with different substrate binding modes were devised. In model A, the bridging hydroxide is assumed to be displaced by one of the substrate oxygens $\left(\mathrm{O}_{\gamma}\right)$. A water molecule that is supposed to act as the nucleophile was manually added to coordinate to $\mathrm{Zn} 1$ and to form a hydrogen bond to Asp55 (the assumed base). Model A is composed of 109 atoms and has an overall charge of +2 . The optimized structure is shown in Figure 2. In the alternative model $\mathrm{B}$, the substrate was assumed to coordinate to $\mathrm{Zn} 1$ and $\mathrm{Zn} 2$ via two of its oxygens, similarly to what has been suggested for endonuclease IV. ${ }^{25} \mathrm{~A}$ water molecule was added to coordinate to $\mathrm{Zn} 2$ and form a hydrogen bond to the leaving oxygen. This Zn2-bound water could function as a general acid to protonate the leaving group $\left(\mathrm{O}_{\mathrm{L}}\right)$. A water molecule occupying a similar position has been observed in the crystal structure of $\mathrm{PLC}_{\mathrm{BC}}$ in complex with inorganic phosphate. ${ }^{26}$ To make the water molecule coordinate to $\mathrm{Zn} 2$ properly, a carboxylate shift of the Glu146 residue was necessary (see Figure 2). This type of phenomena has also been observed in endonuclease IV $^{25}$ and other metalloenzymes. $^{27}$ Model B has a size of 111 atoms and an overall charge of +1 . 

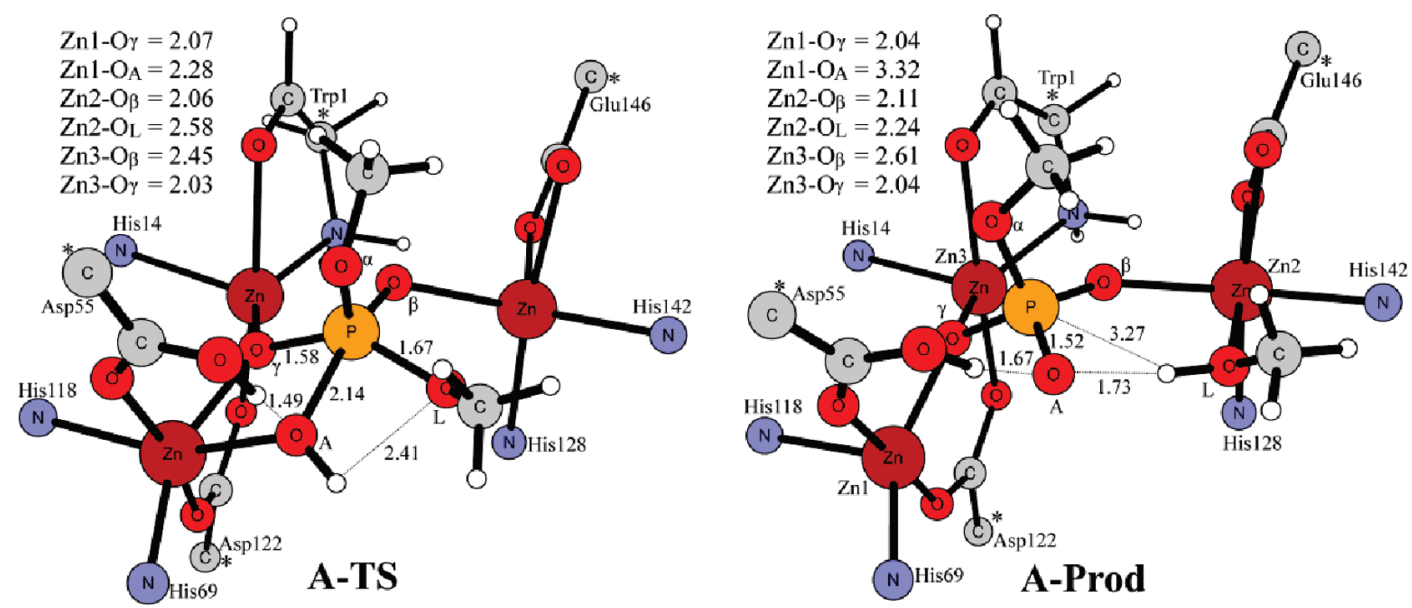

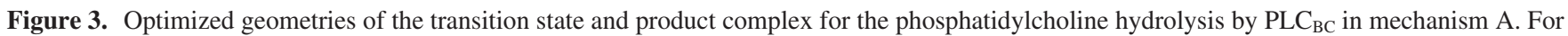
clarity, some residues and hydrogen atoms are not shown, and the histidine ligands are represented by only a nitrogen atom in the figures. The full model can be seen in Figure 2.

\section{Results and Discussion}

IV.1. Mechanism A: Nucleophilic Attack by a Terminal Water Molecule. We first consider the mechanism in which the water molecule bound to $\mathrm{Zn} 1$ is the nucleophile. In the optimized structure of substrate binding mode A (A-React in Figure 2), one of the phosphate oxygens is bridging $\mathrm{Zn} 1$ and Zn3 with quite equal distances, 2.25 and $2.22 \AA$, respectively. The other oxygen $\left(\mathrm{O}_{\beta}\right)$ is asymmetrically bound between $\mathrm{Zn} 2$ and $\mathrm{Zn} 3$, with bond distances of 2.05 and $2.76 \AA$, respectively. The reactive water molecule coordinates to $\mathrm{Zn} 1$ with a distance of $2.22 \AA$ and forms a hydrogen bond to the Asp55 residue. Coordination of water to zinc ions is known to lower its $\mathrm{p} K_{\mathrm{a}}$ significantly (by 7 units or more), ${ }^{28}$ which means that Asp55 can take a proton from the water molecule to generate a hydroxide for the nucleophilic attack. In this mechanism, the nucleophilic attack is adjacent to the leaving group, and not from the back side of the leaving group, as is widely accepted for phosphoesterases. ${ }^{8}$ According to the rules of Westheimer, ${ }^{29}$ nucleophilic attack and leaving group departure are likely to take place only in the axial position of the phosphate. Thus, a Berry pseudorotation process ${ }^{30}$ is required for mechanism A, involving an exchange of two axial ligands $\left(\mathrm{O}_{\mathrm{A}}\right.$ and $\left.\mathrm{O}_{\beta}\right)$ with two equatorial ligands $\left(\mathrm{O}_{\gamma}\right.$ and $\left.\mathrm{O}_{\mathrm{L}}\right)$ in the pentacoordinated trigonal bipyramidal species.

From A-React, the structure of the nucleophilic attack transition state (A-TS) was optimized and is shown in Figure 3 . The barrier is calculated to be $23.8 \mathrm{kcal} / \mathrm{mol}(22.8 \mathrm{kcal} / \mathrm{mol}$ without solvation). At A-TS, the key distance between the water oxygen and the phosphorus center $\left(\mathrm{O}_{\mathrm{A}}-\mathrm{P}\right)$ is $2.14 \AA$, and the distance between leaving methoxide oxygen and phosphorus $\left(\mathrm{O}_{\mathrm{L}}-\mathrm{P}\right)$ is $1.67 \AA$, slightly increased from $1.58 \AA$ in A-React. The simultaneous proton transfer from the water molecule to Asp55 has $\mathrm{O}-\mathrm{H}-\mathrm{O}$ distances of 1.49 and $1.04 \AA$. It is found that the hydroxide attack on the phosphorus center results in the direct elimination of a methanol with a concerted proton transfer from the attacking hydroxide to the leaving methoxy anion $\left(\mathrm{CH}_{3} \mathrm{O}^{-}\right)$to form the product complex (A-Prod in Figure $3)$. No pentacoordinated intermediate was possible to locate and the Berry pseudorotation is seen to be part of the concerted transition state. A More O'Ferral Jencks (MFJ) plot $^{31}$ shows that this concerted transition state has a slightly associative character (see Supporting Information, Figure SI1). The reaction is calculated to be exothermic by as much as $23.0 \mathrm{kcal} / \mathrm{mol}(26.1$ $\mathrm{kcal} / \mathrm{mol}$ without solvation).

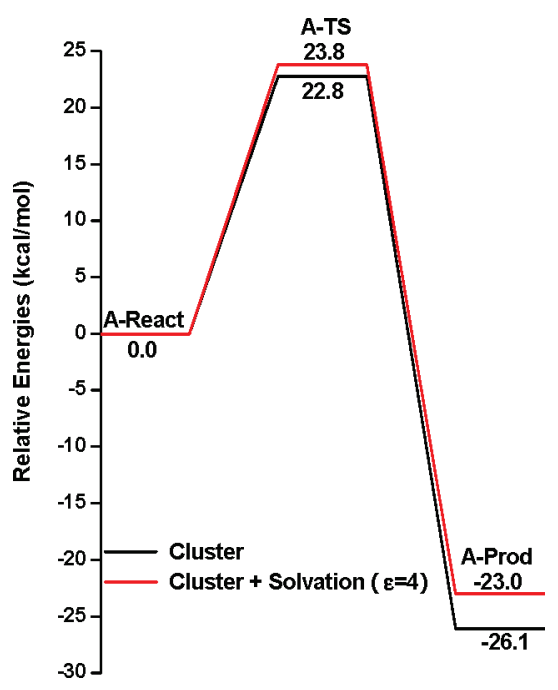

Figure 4. Calculated potential energy profile for mechanism A.

The energies calculated for this mechanism are summarized in Figure 4. The experimental rate constants are measured to be in the range $5-1000 \mathrm{~s}^{-1},{ }^{2 a, 32}$ which can be converted to barriers of around 13-17 kcal/mol using classical transitionstate theory. The calculated barrier for model A $(23.8 \mathrm{kcal} / \mathrm{mol})$ is about $7-10 \mathrm{kcal} / \mathrm{mol}$ higher than the experimental one. Considering that the overall hydrolysis of diethyl phosphate is exothermic by about $2 \mathrm{kcal} / \mathrm{mol},{ }^{33}$ the large exothermicity found for this mechanism indicates that the product complex is very strongly bound to the trinuclear zinc center and that its release will have a high barrier. These two facts strongly argue against the terminal water molecule being the nucleophile in the PLC reaction.

IV.2. Mechanism B: Nucleophilic Attack by a Bridging Hydroxide. In the alternative mechanism $B$, the hydroxide bridging Zn1 and Zn3 perform the nucleophilic attack. ${ }^{15}$ This mechanism was criticized on the basis of the fact that the bridging hydroxide is replaced by one oxygen of the substrate analogue 3,4-di- $n$-hexanoyloxybutyl-1-phosphocholine. ${ }^{11} \mathrm{How}-$ ever, the other trinuclear zinc enzymes NP1 and endonuclease IV are assumed to adopt this mechanism. Also, an inhibitor structure does not necessarily reflect the correct substrate binding mode. We therefore decided to investigate the energetics of such a mechanism. The optimized structure of the Michaelis complex (here termed B-React) for model B is shown in Figure 2. The 

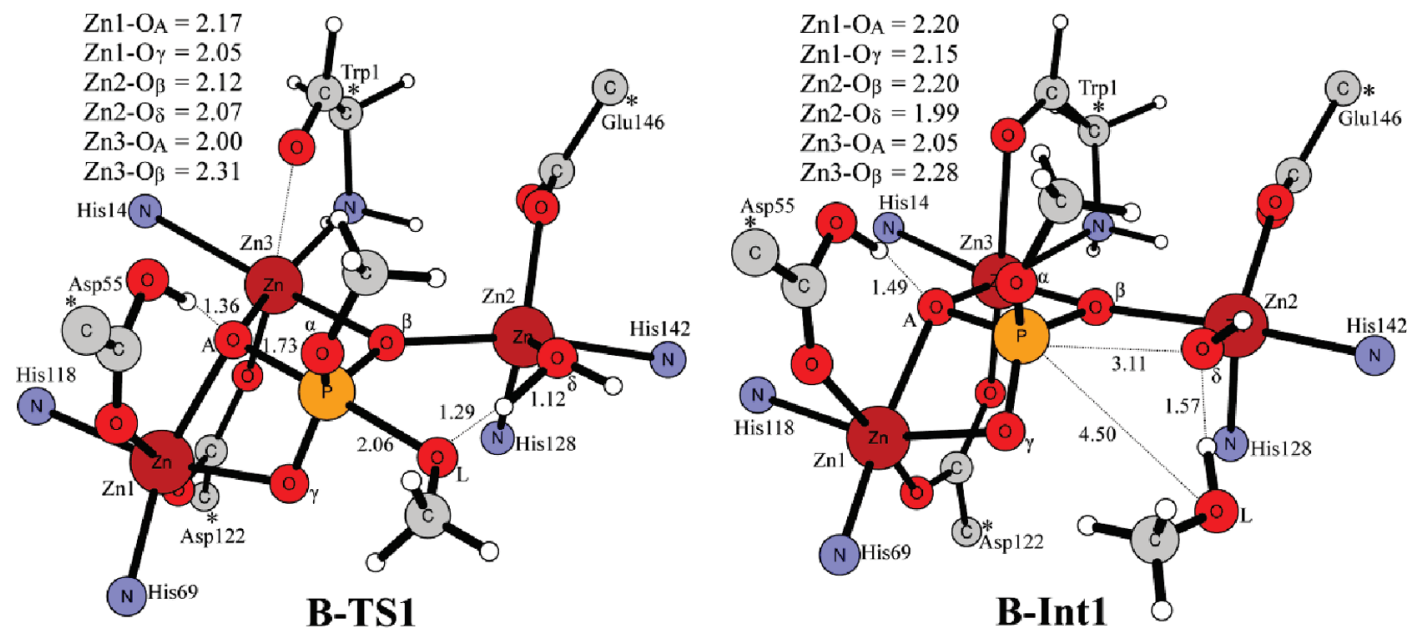

Figure 5. Optimized geometries of the transition state and intermediate in mechanism B.

substrate coordinates to $\mathrm{Zn} 1$ and $\mathrm{Zn} 2$ with two of its phosphate oxygens, with a $\mathrm{Zn} 1-\mathrm{O}_{\gamma}$ distance of $2.21 \AA$ and a $\mathrm{Zn} 2-\mathrm{O}_{\beta}$ distance of $2.06 \AA$. A weak interaction is observed between the substrate and the $\mathrm{Zn} 3$ ion $\left(\mathrm{Zn} 3-\mathrm{O}_{\beta}: 3.59 \AA\right)$. There is also a hydrogen bond between the leaving oxygen $\left(\mathrm{O}_{\mathrm{L}}\right)$ and the $\mathrm{Zn} 2$ bound water molecule. These interactions help to orient the substrate such that there is a nearly straight line between $\mathrm{O}_{\mathrm{A}}-\mathrm{P}$ $\mathrm{O}_{\mathrm{L}}$, with an angle of $175.6^{\circ}$. The improper dihedral angle $\mathrm{O}_{\beta}-\mathrm{P}-\mathrm{O}_{\alpha}-\mathrm{O}_{\gamma}$ is $136.8^{\circ}$, to be compared to $121.9^{\circ}$ formed by $\mathrm{O}_{\gamma}-\mathrm{P}-\mathrm{O}_{\alpha}-\mathrm{O}_{\mathrm{L}}$ in A-React. This indicates a more accessible conformation for nucleophilic attack in B-React. The $\mathrm{O}_{\mathrm{A}}-\mathrm{P}$ distance is $2.92 \AA$ and the substrate in this binding mode is thus well-arranged for the nucleophilic attack.

In general, the nucleophilic attack can result in a pentacoordinated trigonal bipyramidal intermediate, like in phosphotriesterase, ${ }^{19 \mathrm{a}}$ DNA polymerase $\beta,{ }^{\text {if }}$ DNA polymerase $\mathrm{IV},{ }^{9 \mathrm{~g}}$ ribonuclease $\mathrm{A},{ }^{9 \mathrm{j}}$ and ribonuclease $\mathrm{H},{ }^{9 \mathrm{k}}$ for example. However, in the case of PLC, a concerted $\mathrm{S}_{\mathrm{N}} 2$-type transition state B-TS1 (Figure 5) was found, without the formation of a pentacoordinated intermediate. This is similar to the results found for endonuclease IV,${ }^{25}$ myosin, ${ }^{90}$ cAMP-dependent protein kinase, ${ }^{9 p}$ cyclin-dependent kinase $\mathrm{Cdk} 2,{ }^{9 \mathrm{q}}$ human uridinecytidine kinase $2,{ }^{9 \mathrm{~s}}$ and RNase $\mathrm{Z} .{ }^{19 \mathrm{f}} \mathrm{We}$ find that the nucleophilic attack occurs directly from the bridging position, similarly to all the dinuclear zinc enzymes studied previously. ${ }^{19}$ Two proton transfers take place concertedly at the same B-TS1 transition state. The $\mathrm{Zn} 2$-bound water molecule protonates the leaving group, facilitating thereby its release, while Asp55 abstracts a proton from the bridging hydroxide, increasing thereby its nucleophilic power. The nature of B-TS1 was confirmed to have an imaginary frequency of $195 i \mathrm{~cm}^{-1}$, corresponding to the $\mathrm{O}_{\mathrm{A}}-\mathrm{P}$ bond formation and $\mathrm{P}-\mathrm{O}_{\mathrm{L}}$ bond cleavage, coupled with proton transfers from the bridging hydroxide to Asp55 and from the $\mathrm{Zn} 2$-bound water to $\mathrm{O}_{\mathrm{L}}$. The barrier is calculated to be 17.3 $\mathrm{kcal} / \mathrm{mol}(20.9 \mathrm{kcal} / \mathrm{mol}$ without solvation), which is $6.5 \mathrm{kcal} /$ mol lower than the barrier obtained for mechanism A. At B-TS1, the nascent $\mathrm{P}-\mathrm{O}_{\mathrm{A}}$ bond is $1.73 \AA$, and the scissile $\mathrm{P}-\mathrm{O}_{\mathrm{L}}$ bond is $2.06 \AA$. The $\mathrm{Zn} 1-\mathrm{O}_{\gamma}$ and $\mathrm{Zn} 3-\mathrm{O}_{\beta}$ distances become considerably shorter $(2.05$ and $2.31 \AA$, respectively), which indicates these two zinc ions provide electrostatic stabilization to the transition state, thereby lowering the barrier. As in the case of A-TS, MFJ analysis (Supporting Information, Figure SI2) shows that B-TS1 is slightly associative. Downhill from B-TS1, the intermediate B-Int1 is formed (Figure 5), in which the protonated leaving alcohol has dissociated and a hydroxide is bound to $\mathrm{Zn} 2$. This species is calculated to be only $0.1 \mathrm{kcal} /$ mol (1.5 kcal/mol without solvation) higher than B-React. The leaving alcohol can easily be released to the solution as it is only hydrogen-bonded to the $\mathrm{Zn} 2$ bound hydroxide.

After the release of the alcohol, the following steps involve the regeneration of the bridging hydroxide which can start a new catalytic cycle. Two possibilities can be envisioned here. In the first, the newly generated Zn2-bound hydroxide acts as a nucleophile to reverse the reaction. In the second, it acts as a base to activate a water molecule that attacks the phosphorus center. Both these two scenarios were considered here.

To study the nucleophile mechanism, we simply removed the alcohol from B-Int1 and reoptimized the structure (called B-Int2a, Figure 6). We then optimized the transition state for the hydroxide attack at the phosphorus center (B-TS2a, Figure 6). The barrier is calculated to be only $8.1 \mathrm{kcal} / \mathrm{mol}(3.9 \mathrm{kcal} /$ mol without solvation) relative to B-Int2a, and the step is calculated to be exothermic by $3.9 \mathrm{kcal} / \mathrm{mol}(7.1 \mathrm{kcal} / \mathrm{mol}$ without solvation). This nucleophilic attack results in the direct cleavage of the $\mathrm{P}-\mathrm{O}_{\mathrm{A}}$ bond and the formation of the product complex (B-Proda, Figure 6), completing hence the catalytic cycle. At B-TS2a, the $\mathrm{P}-\mathrm{O}_{\delta}$ distance is $2.20 \AA$, while the $\mathrm{P}-\mathrm{O}_{\mathrm{A}}$ bond distance is $1.70 \AA$ A Simultaneously, a proton is transferred back from Asp55 to the bridging oxygen $\left(\mathrm{O}_{\mathrm{A}}\right)$. Thus, Asp55 acts first as a general base to accept a proton from the bridging hydroxide and then as a general acid to offer a proton to regenerate the bridging hydroxide. This is similar to the function of Asp67 in the dinuclear zinc enzyme RNase Z. ${ }^{19 f}$ The results thus explain why Asp55 is a critical residue for catalysis, as its mutation results in a $10^{6}$-fold drop in activity. ${ }^{13 \mathrm{c}}$

Due to the weaker interaction between $\mathrm{Zn} 2$ and $\mathrm{O}_{\delta}$ in B-Proda, Glu146 is now bound in a bidentate fashion to $\mathrm{Zn} 2$.

To investigate the alternative base pathway, the alcohol of B-Int1 was replaced by a water molecule to form B-Int2b (Figure 6). Due to the similar $\mathrm{p} K_{\mathrm{a}}$ values of hydroxide and methoxide, this path looks like a mirror image of the first halfreaction. The transition state $\mathrm{B}-\mathrm{TS} 2 \mathrm{~b}$ (Figure 6) is found to have a geometry similar to that for B-TS1. The barrier is calculated to be $18.9 \mathrm{kcal} / \mathrm{mol}(18.6 \mathrm{kcal} / \mathrm{mol}$ without solvation) relative to B-Int2b. This is $10.8 \mathrm{kcal} / \mathrm{mol}(15.7 \mathrm{kcal} / \mathrm{mol}$ without solvation) higher than that for the direct Zn2-bound hydroxide attack. Thus, the calculations show that there is no need of an additional water molecule for the formation of the final product and the regeneration of the bridging hydroxide. 


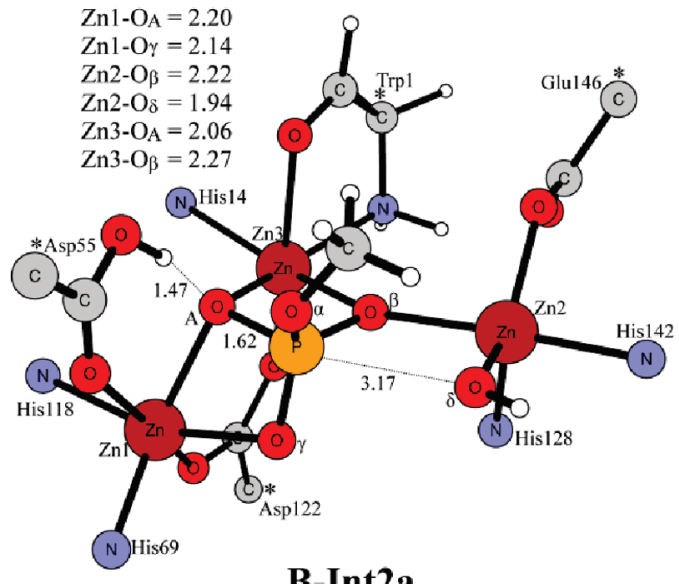

B-Int2a

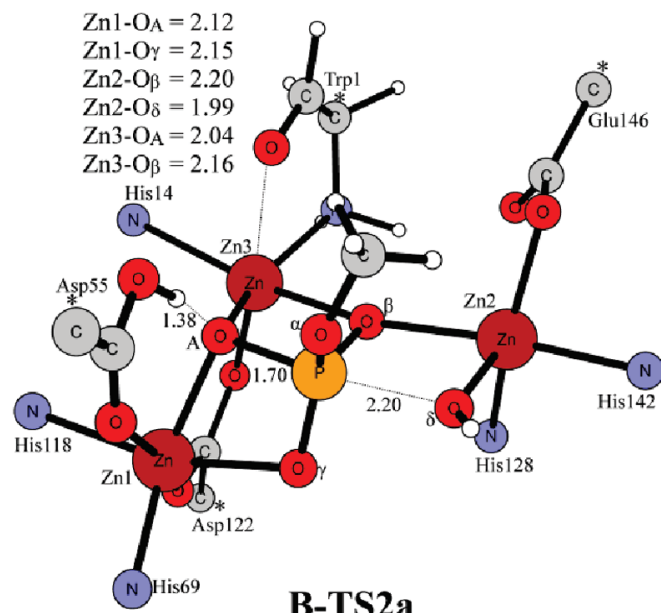

B-TS2a

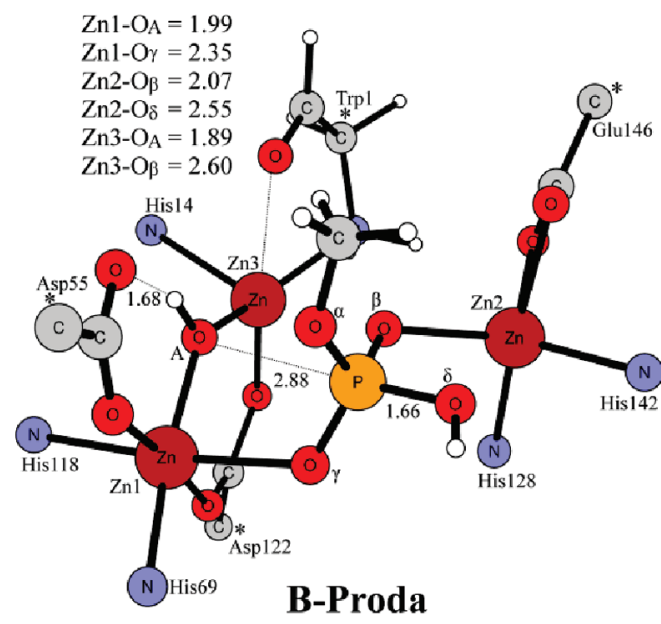

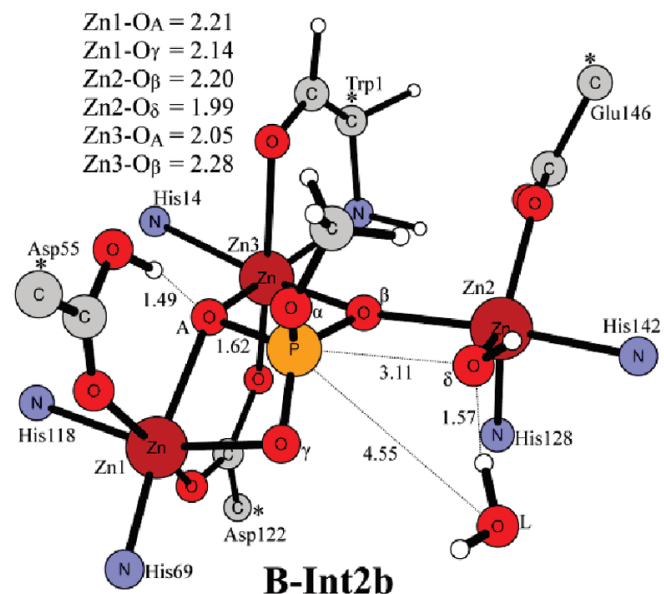
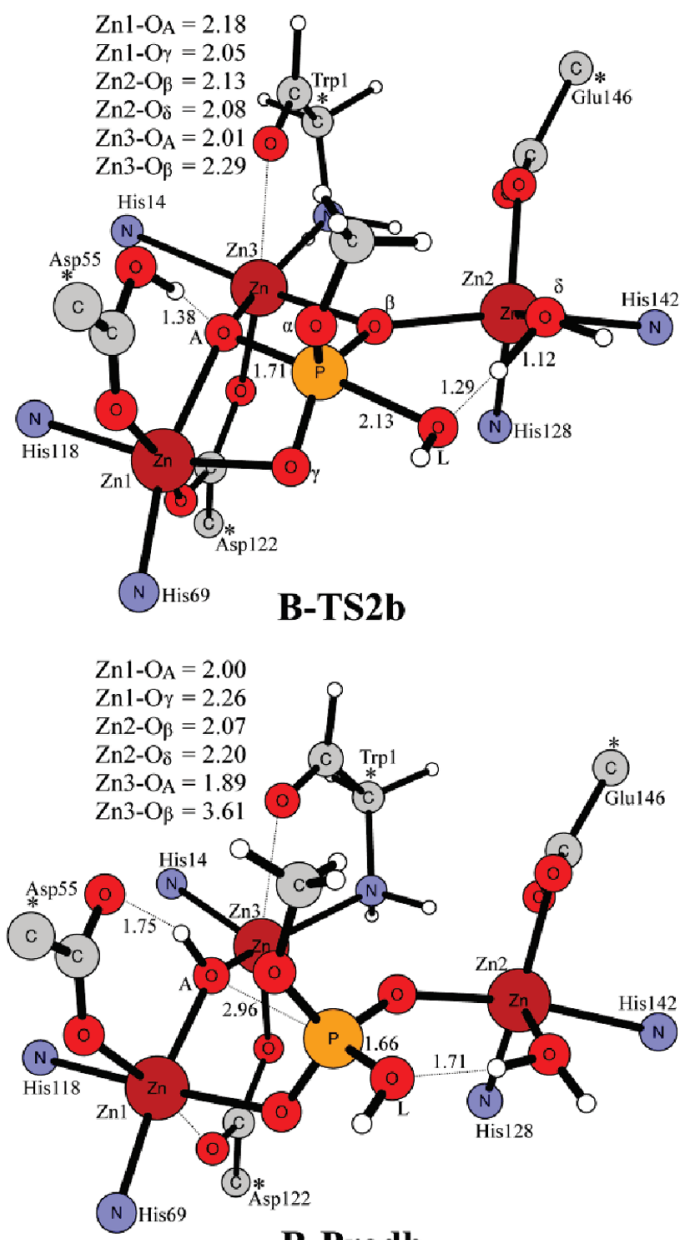

B-Prodb

Figure 6. Optimized geometries for the intermediates, transition states, and products for the second half of mechanism B.

The energies calculated for mechanism B are summarized in Figure 7. The first step determines the reaction rate with a barrier of $17.3 \mathrm{kcal} / \mathrm{mol}$. This agrees very well with the $13-17 \mathrm{kcal} /$ mol barriers estimated from the experimental rate constants. ${ }^{2 a, 32}$

IV.3. Deuterium Isotope Effect. On the basis of solvent viscosity experiments coupled with the observed normal deuterium isotope effect $\left(k_{\mathrm{H}} / k_{\mathrm{D}}=1.9\right)$, a proton transfer was implicated in the rate-determining step. ${ }^{34}$ It seems that a zincbound water molecule may not be a viable option for the nucleophilic attack in $\mathrm{PLC}_{\mathrm{BC}}$, since inverse isotope effects have been detected for several enzymes that utilize zinc-bound waters as nucleophiles, such as AMP deaminase, ${ }^{35}$ thermolysin, ${ }^{36}$ stromelysin, ${ }^{37}$ and desuccinylase. ${ }^{38}$

Here, we have calculated the deuterium isotope effects for both mechanism A and B. This was done by recalculating the zero-point energies from the harmonic frequencies using the mass of deuterium instead of proton for the water molecule bound to $\mathrm{Zn} 1$ in mechanism $\mathrm{A}$ and $\mathrm{Zn} 2$ in mechanism $\mathrm{B}$. The computed ZPE difference is then converted to isotope effect using classical transition-state theory.

For mechanism B, the calculations yield a normal isotope effect of 2.2, which is derived from a barrier increase of 0.47 


\section{SCHEME 3: Proposed Reaction Mechanism for $\mathrm{PLC}_{\mathrm{BC}}$ Based on the Present Quantum Chemical Calculations}

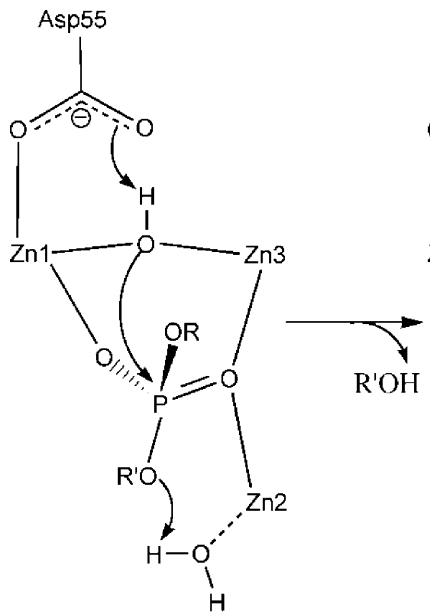

B-React

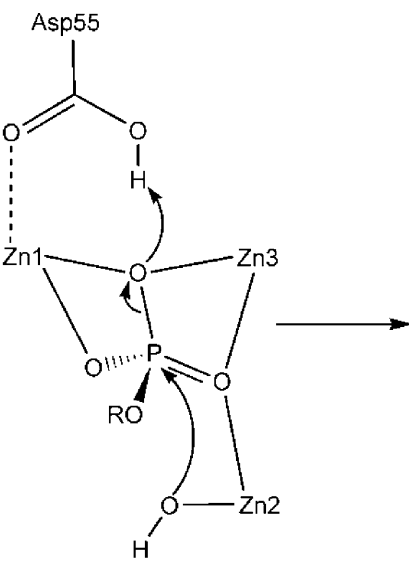

B-Int2a

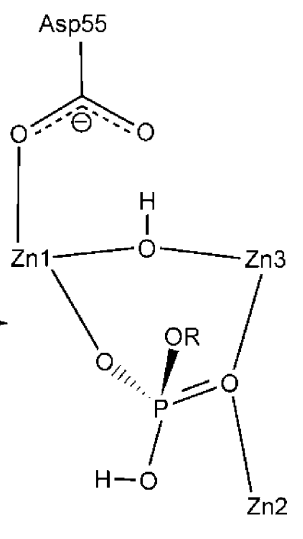

B-Proda $\mathrm{kcal} / \mathrm{mol}$. This value is very close to the experimental one of 1.9. ${ }^{34}$ For mechanism A, however, the barrier increases by only $0.02 \mathrm{kcal} / \mathrm{mol}$, corresponding to a normal isotope effect of 1.04 . These findings, thus, further corroborate the results discussed above, namely that mechanism B is more favored and that the bridging hydroxide is the nucleophile.

\section{Conclusions}

In the present paper, the reaction mechanism of phosphodiester hydrolysis by $\mathrm{PLC}_{\mathrm{BC}}$ has been investigated using the hybrid DFT method B3LYP. Two quantum chemical models based on two different mechanistic scenarios were devised and transition states and intermediates along the reaction pathways were located. Our results show that the reaction mechanism shown in Scheme 3 is energetically more feasible. The phosphate group of the substrate binds to the trinuclear zinc cluster mainly through direct coordination to $\mathrm{Zn} 1$ and $\mathrm{Zn} 2$, and hydrogen bonding to the $Z n 2$-bound water molecule. The hydroxide bridging $\mathrm{Zn} 1$ and $\mathrm{Zn} 3$ makes the nucleophilic attack on the phosphorus center, concertedly with the dissociation of the leaving alkoxide, which takes a proton from the Zn2-bound water molecule. In the subsequent step, the $\mathrm{Zn} 2$ bound hydroxide makes a reverse attack, resulting in the regeneration of the bridging hydroxide. The first step is rate-limiting and the barrier is calculated to be $17.3 \mathrm{kcal} / \mathrm{mol}$, in good agreement with experimental kinetic studies. In this mechanism, all three zinc ions provide catalytic power by electrostatic stabilization of the transition states. Asp55 acts first as a general base to accept a

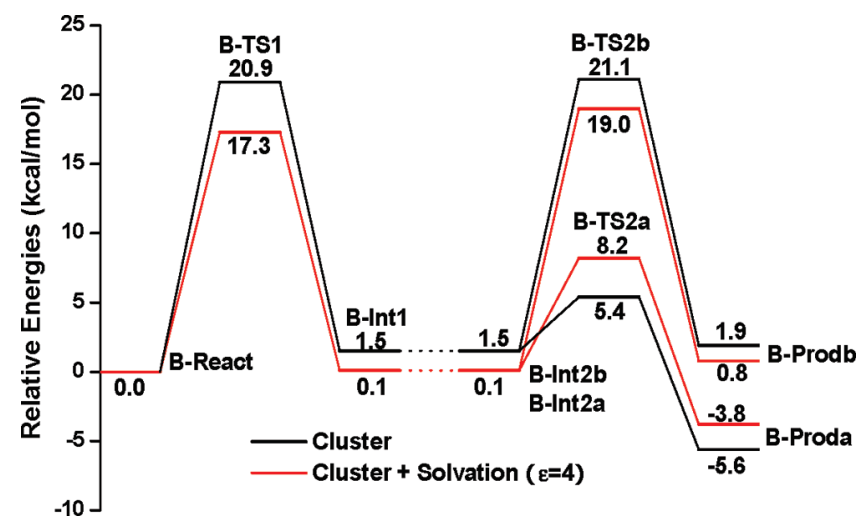

Figure 7. Calculated potential energy diagram for the phosphatidylcholine hydrolysis by $\mathrm{PLC}_{\mathrm{BC}}$ in mechanism $\mathrm{B}$. proton from the bridging hydroxide in the first step, and then as a general acid to return it in the second step.

Acknowledgment. F.H. gratefully acknowledges financial support from The Swedish National Research Council (VR) and The Carl Trygger Foundation. This work was also supported by grants from the National Natural Science Foundation of China (Grant Nos. 20733002 and 20873008).

Supporting Information Available: Complete list of authors for ref 20, MFJ plots, and coordinates for all structures. This material is available free of charge via the Internet at http:// pubs.acs.org.

\section{References and Notes}

(1) (a) Exton, J. H. Eur. J. Biochem. 1997, 243, 10-20. (b) Exton, J. H. J. Biol. Chem. 1990, 265, 1-4.

(2) (a) Hergenrother, P. J.; Martin, S. F. Anal. Biochem. 1997, 251, 45-49. (b) Hergenrother, P. J.; Martin, S. F. Top. Curr. Chem. 2001, 211, 131-167. (c) Berridge, M. J. Biochem. J. 1984, 220, 345-360. (d) Titball, R. W. Microbiol. Rev. 1993, 57, 347-366.

(3) Berridge, M. J. Annu. Rev. Biochem. 1987, 56, 159-193.

(4) (a) Clark, M. A.; Shorr, R. G. L.; Bomalaski, J. S. Biochem. Biophys. Res. Commun. 1986, 140, 114-119. (b) de Herreros, A. G.; Dominguez, I.; Diaz-Meco, M. T.; Graziani, G.; Cornet, M. E.; Guddal, P. H.; Johansen, T.; Moscat, J. J. Biol. Chem. 1991, 266, 6825-6829. (c) Larrodera, P.; Cornet, M. E.; Diaz-Meco, M. T.; Lopez-Barahona, M.; Diaz-Laviada, I.; Guddal, P. H.; Johansen, T.; Moscat, J. Cell 1990, 6, 1113-1120. (d) Johansen, T.; Bjorkoy, G.; Overatn, A.; Diaz-Meco, M. T.; Traavik, T.; Moscat, J. Mol. Cell. Biol. 1994, 14, 646-654.

(5) Hough, E.; Hansen, L. K.; Birknes, B.; Jynge, K.; Hansen, S.; Hordvik, A.; Little, C.; Dodson, E.; Derewenda, Z. Nature 1989, 338, 357360.

(6) (a) Romier, C.; Dominguez, R.; Lahm, A.; Dahl, O.; Suck, D. Proteins 1998, 32, 414-424. (b) Naik, A. K.; Raghavan, S. C. DNA Repair 2008, 7, 1384-1391.

(7) (a) Hosfield, D. J.; Guan, Y.; Haas, B. J.; Cunningham, R. P.; Tainer, J. A. Cell 1999, 98, 397-408. (b) Garcin, E. D.; Hosfield, D. J.; Desai, S. A.; Haas, B. J.; Björas, M.; Cunningham, R. P.; Tainer, J. A. Nat. Struc. Mol. Biol. 2008, 15, 515-522.

(8) (a) Cleland, W. W.; Hengge, A. C. Chem. Rev. 2006, 106, 32523278. (b) Jackson, M. D.; Denu, J. M. Chem. Rev. 2001, 101, 2313-2340. (c) Holmes, R. R. Acc. Chem. Res. 2004, 37, 746-753. (d) Vetter, I. R.; Wittinghofer, A. Q. Rev. Biophys. 1999, 32, 1-56. (e) Blume-Jensen, P.; Hunter, T. Nature 2001, 411, 355-365. (f) Lahiri, S. D.; Zhang, G.; Dunaway-Mariano, D.; Allen, K. N. Science 2003, 299, 2067-2071.

(9) See for example: (a) Florián, J.; Warshel, A. J. Phys. Chem. B 1998, 102, 719-734. (b) Kamerlin, S. C. L.; McKenna, C. E.; Goodman, M. F.; Warshel, A. Biochemistry 2009, 48, 5963-5971. (c) Rosta, E.; Kamerlin, S. C. L.; Warshel, A. Biochemistry 2008, 47, 3725-3735. (d) Klähn, M.; Rosta, E.; Warshel, A. J. Am. Chem. Soc. 2006, 128, 1531015323. (e) Florián, J.; Goodman, M. F.; Warshel, A. J. Am. Chem. Soc. 2003, 125, 8163-8177. (f) Alberts, I. L.; Wang, Y.; Schlick, T. J. Am. Chem. 
Soc. 2007, 129, 11100-11110. (g) Wang, L.; Yu, X.; Hu, P.; Broyde, S. Zhang, Y. J. Am. Chem. Soc. 2007, 129, 4731-4737. (h) Nam, K.; Gao, J.; York, D. M. J. Am. Chem. Soc. 2008, 130, 4680-4691. (i) Wang, Y.; Schlick, T. J. Am. Chem. Soc. 2008, 130, 13240-13250. (j) Elsässer, B.; Valiev, M.; Weare, J. H. J. Am. Chem. Soc. 2009, 131, 3869-3871. (k) De Vivo, M.; Dal Peraro, M.; Klein, M. L. J. Am. Chem. Soc. 2008, 130, 1095510962. (1) Turjanski, A. G.; Hummer, G.; Gutkind, J. S. J. Am. Chem. Soc. 2009, 131, 6141-6148. (m) Lee, T.-S.; Lǒpez, C. S.; Giambasu, G. M.; Martick, M.; Scott, W. G.; York, D. M. J. Am. Chem. Soc. 2008, 130, 3053 3064. (n) Wang, Y.-N.; Topol, I. A.; Collins, J. R.; Burt, S. K. J. Am. Chem Soc. 2003, 125, 13265-13273. (o) Grigorenko, B. L.; Rogov, A. V.; Topol, I. A.; Burt, S. K.; Martinez, H. M.; Nemukhin, A. V. Proc. Natl. Acad. Sci. U.S.A. 2007, 104, 7057-7061. (p) Chen, Y.; Zhang, Y.; McCammon, J. A. J. Am. Chem. Soc. 2005, 127, 1553-1562. (q) De Vivo, M.; Cavalli, A.; Carloni, P.; Recanatini, M. Chem.-Eur. J. 2007, 13, 8437-8444. (r) Lin, P.; Pedersen, L. C.; Batra, V. K.; Beard, W. A.; Wilson, S. H.; Pedersen, L. G. Proc. Natl. Acad. Sci. U. S. A. 2006, 103, 13294-13299. (s) Smith,

A. J. T.; Li, Y.; Houk, K. N. Org. Biomol. Chem. 2009, 7, 2716-2724.

(10) Strater, N.; Lipscomb, W. N.; Klabunde, T.; Krebs, B. Angew. Chem., Int. Ed. 1996, 35, 2024-2055.

(11) (a) Hansen, S.; Hough, E.; Svensson, L. A.; Wong, Y.-L.; Martin, S. F. J. Mol. Biol. 1993, 234, 179-187. (b) Hansen, S.; Hansen, L. K.; Hough, E. J. Mol. Biol. 1993, 231, 870-876. (c) Antikainen, N. M.; Monzingo, A. F.; Franklin, C. L.; Robertus, J. D.; Martin, S. F. Arch. Biochem. Biophys. 2003, 417, 81-86.

(12) Martin, S. F.; Spaller, M. R.; Hergenrother, P. J. Biochemistry 1996, $35,12970-12977$.

(13) (a) Antikainen, N. M.; Hergenrother, P. J.; Harris, M. M.; Corbett, W.: Martin, S. F. Biochemistry 2003, 42, 1603-1610. (b) Martin, S. F. Follows, B. C.; Hergenrother, P. J.; Trotter, B. K. Biochemistry 2000, 39 3410-3415. (c) Martin, S. F.; Hergenrother, P. J. Biochemistry 1998, 37, 5755-5760. (d) Benfield, A. P.; Goodey, N. M.; Phillips, L. T.; Martin, S. F. Arch. Biochem. Biophys. 2007, 460, 41-47.

(14) Thrige, D. D.; Buur, J. R. B.; Jorgensen, S. F. Biopolym. 1997, 42, 319-336. 577.

(15) Sundell, S.; Hansen, S.; Hough, E. Protein Eng. 1994, 7, 571-

(16) (a) Weston, J. Chem. Rev. 2005, 105, 2151-2174. (b) Parkin, G. Chem. Rev. 2004, 104, 699-768. (c) Lipscomb, W. N.; Strater, N. Chem. Rev. 1996, 96, 2375-2434.

(17) (a) Becke, A. D. J. Chem. Phys. 1993, 98, 5648-5652. (b) Lee, C.; Yang, W.; Parr, R. G. Phys. Rev. B 1988, 37, 785-789.

(18) (a) Himo, F.; Siegbahn, P. E. M. Chem. Rev. 2003, 103, 24212456. (b) Noodleman, L.; Lovell, T.; Han, W.-G.; Li, J.; Himo, F. Chem Rev. 2004, 104, 459-508. (c) Siegbahn, P. E. M.; Borowski, T. Acc. Chem Res. 2006, 39, 729-738. (d) Himo, F. Theo. Chem. Acc. 2006, 116, 232240. (e) Ramos, M. J.; Fernandes, P. A. Acc. Chem. Res. 2008, 41, 689698. (f) Himo, F.; Siegbahn, P. E. M. J. Biol. Inorg. Chem. 2009, 14, 643 651. (g) Siegbahn, P. E. M. J. Biol. Inorg. Chem. 2006, 11, 695-701.

(19) (a) Chen, S.-L.; Fang, W.-H.; Himo, F. J. Phys. Chem. B 2007, 111, 1253-1255. (b) Chen, S.-L.; Marino, T.; Fang, W.-H.; Russo, N.; Himo, F. J. Phys. Chem. B 2008, 112, 2494-2500. (c) Liao, R.-Z.; Yu, J.-G.;
Raushel, F. M.; Himo, F. Chem.-Eur. J. 2008, 14, 4287-4292. (d) Liao, R.-Z.; Yu, J.-G.; Himo, F. Inorg. Chem. 2009, 48, 1442-1448. (e) Chen, S.-L.; Fang, W.-H.; Himo, F. J. Inorg. Biochem. 2009, 103, 274-281. (f) Liao, R.-Z.; Himo, F.; Yu, J.-G.; Liu, R.-Z. Eur. J. Inorg. Chem. 2009, 20, 2967-2972. (g) Liao, R.-Z.; Himo, F.; Yu, J.-G.; Liu, R.-Z. J. Inorg. Biochem. 2010, 104, 37-46.

(20) Frisch, M. J.; et al. Gaussian 03, Revision D.01; Gaussian, Inc.: Wallingford, CT, 2004.

(21) Hay, P. J.; Wadt, W. R. J. Chem. Phys. 1985, 82, 270-283.

(22) (a) Klamt, A.; Schüürmann, G. J. Chem. Soc., Perkin. Trans. 1993, 2, 799-805. (b) Andzelm, J.; Kölmel, C.; Klamt, A. J. Chem. Phys. 1995, 103, 9312-9320. (c) Barone, V.; Cossi, M. J. Phys. Chem. A 1998, 102, 1995-2001. Cossi, M.; Gega, N.; Scalmani, G.; Barone, V. J. Comput. Chem. 2003, 24, 669-691.

(23) (a) Sevastik, R.; Himo, F. Bioorg. Chem. 2007, 35, 444-457. (b) Hopmann, K. H.; Himo, F. J. Chem. Theor. Comp. 2008, 4, 1129-1137.

(c) Georgieva, P.; Himo, F. J. Comput. Chem., in press.

(24) Hu, P.; Zhang, Y. J. Am. Chem. Soc. 2006, 128, 1272-1278.

(25) Ivanov, I.; Tainer, J. A.; McCammon, J. A. Proc. Natl. Acad. Sci. U.S.A. 2007, 104, 1465-1470.

(26) Hansen, S.; Hansen, L. K.; Hough, E. J. Mol. Biol. 1992, 225, 543549

(27) See for example: (a) Covarrubias, A. S.; Bergfors, T.; Jones, T. A.; Högbom, M. J. Biol. Chem. 2006, 281, 4993-4999. (b) Moche, M.; Shanklin, J.; Ghoshal, A.; Lindqvist, Y. J. Biol. Chem. 2003, 278, 25072-25080. (c) Andersson, M. E.; Högbom, M.; Rinaldo-Matthis, A.; Andersson, K. K.; Sjöberg, B.; Nordlund, P. J. Am. Chem. Soc. 1999, 121, 2346-2352. (d) Gherman, B. F.; Baik, M. H.; Lippard, S. J.; Friesner, R. A. J. Am. Chem. Soc. 2004, 126, 2978-2990. (e) Sousa, S. F.; Fernandes, P. A.; Ramos, M. J. J. Am. Chem. Soc. 2007, 129, 1378-1385.

(28) Galder, A.; Vallee, B. L. In Metal ions in biological systems; Siegel,

H., Ed.; Dekker: New York, 1983; Vol. 15, pp 6-7.

(29) Westheimer, F. H. Acc. Chem. Res. 1968, 1, 70-78.

(30) Berry, R. S. J. Chem. Phys. 1960, 32, 933-938.

(31) (a) More O'Ferral, R. A. J. Chem. Soc. B 1970, 274-277. (b) Jencks, W. P. Chem. Rev. 1985, 85, 511-527.

(32) (a) Tan, C. A.; Roberts, M. F. Biochemistry 1998, 37, 4275-4279. (b) Martin, S. F.; Hergenrother, P. J. Bioorg. Med. Chem. Lett. 1998, 8, 593-596.

(33) Gerlt, J. A.; Westheimer, F. H.; Sturtevant, J. M. J. Biol. Chem. 1975, 250, 5059-5067.

(34) Martin, S. F.; Hergenrother, P. J. Biochemistry 1999, 38, 44034408

(35) Merkler, D. J.; Schramm, V. L. Biochemistry 1993, 32, 5792-5799.

(36) Izquierdo, M. C.; Stein, R. L. J. Am. Chem. Soc. 1990, 112, 60546062

(37) Harrison, R. K.; Chang, B.; Niedzwiecki, L.; Stein, R. L. Biochemistry 1992, 31, 10757-10762.

(38) Born, T. L.; Zheng, R.; Blanchard, J. S. Biochemistry 1998, 37, 10478-10487.

JP910992F 